УДК 316

\title{
ПРОЦЕСС СМЕНЫ ПАСПОРТНОГО ПОЛА ТРАНСГЕНДЕРНЫМИ ЛЮДЬМИ В РОССИИ
}

Теодори Данте Николаевич

магистр социологии

Санкт-Петербургская школа социальных наук и востоковедения

Национальный исследовательский университет

«Высшая школа экономики»

\begin{abstract}
Аннотация: данное исследование посвящено процессу смены паспортного пола трансгендерными людьми в России. Целью исследования стало определение сути смены паспортного пола, его границ, особенностей, выделение акторов, существующих в этом поле и логики их взаимодействия. Автор определил этапы процесса трансгендерного перехода, выделил обязательные и вариативные сценарии поведения.
\end{abstract}

Ключевые слова: гендерные исследования, гендер, трансгендер, смена паспортного пола, переход, бюрократия.

\section{THE PROCESS OF CHANGING LEGAL SEX BY TRANSGENDER PEOPLE IN RUSSIA}

\section{Teodori Dante Nikolaevich}

\begin{abstract}
This study is devoted to the process of changing the legal sex of transgender people in Russia. The purpose of the study was to determine the essence of changing the legal sex, its boundaries, features, the selection of actors existing in this field and the logic of their interaction. The author defined the stages of the transgender transition process, identified mandatory and variable behavior scenarios.

Key words: gender studies, gender, transgender, change of legal sex, transition, bureaucracy.
\end{abstract}

Смена документов трансгендерными людьми - тема, отсутствующая в отечественной социологии и по сути относительно широко представленная только в психиатрии. Тем не менее, как и представители других групп, люди, меняющие документы с связи со сменой паспортного пола, проходят 
определенные стадии и сталкиваются с определенными трудностями при взаимодействии с бюрократическим аппаратом, и изучение данной темы поможет выявить и описать логику этого взаимодействия, чтобы в конечном счете обеспечить базу для практических изменений в этой области.

Сама смена документов при трансгендерном переходе в России имеет свои особенности и отличия от западного опыта как смены документов, так и исследования этого вопроса [1]. Отличия не идут по бинарной модели “отсталая Россия - прогрессивный Запад”. По каждому из этапов и по каждой стране можно говорить об отлаженности или же непроработанности регламента [2, с. 25-33]. Мы не можем говорить об опыте одной страны как об оптимальном и опыте другой как о максимально непроработанном. Возникает вопрос, можно ли назвать сложившуюся ситуацию удовлетворительной или удовлетворяющей участников этих отношений и может ли данная инфраструктура производить особые социальные и властные отношения.

Данное исследование опирается на логику действий Международной классификации болезней 10-го пересмотра [3], где для смены паспортного пола необходима постановка диагноза. Это “Транссексуализм”, который относится к расстройствам личности и поведения в зрелом возрасте, а именно, расстройствам половой идентификации.

Почему эта тема важна как для трансгендерного сообщества, так и для социологии в целом?

1.В России нет академических социологических исследований, описывающих как сам процесс трансгендерного перехода, так и часть, связанную именно со сменой паспортного пола. Нет четко прописанных терминов (обычно используются термины из психиатрии), нет понимания: в чем суть этого процесса? С чего он начинается и чем заканчивается? После получения какого документа он считается завершенным?

2. Ряд западных социологических исследований, посвященных проблеме смены паспортного пола, подчеркивают, что изучение этого процесса, а также влияния упрощения этой процедуры способствует улучшению состояния трансгендерных людей, увеличению уровня их дохода, снижению смертности и снижению последствий дискриминации [4].

3. Не прописана специфика взаимодействия с бюрократическим аппаратом в случае смены паспортного пола. Какие отличия имеет этот процесс у трансгендерных людей по отношению к другим людям, также вынужденным 
менять документы по разным причинам: в связи с переездом, сменой брачного статуса и т.п.

4. Смена документов у трансгендеров - это еще и вопрос приватного, в которое вторгаются механизмы контроля тела.

Объектом данного исследования стали люди с предписанным женским гендерным маркером, прошедшие сертифицированную комиссию по определению диагноза F64.0 до вступления в силу МКБ 11 с целью сменить женский гендерный маркер на мужской.

Предмет исследования - процесс смены паспортного пола трансгендерными людьми в России. Исследовательский вопрос: Что представляет из себя процесс смены документов трансгендерными людьми и на что это похоже?

Задачами стало изучение опыта смены паспортного пола трансгендерными людьми в России, анализ специфики властных отношений в процессе перехода, изучение истории трансгендерного перехода респондентов и попытка очертить логику трансгендерного перехода в России.

Выбрано несколько методов исследования: включенное наблюдение и его анализ, исследование закрытых чатов трансгендерных людей в Интернете, интервью. Это помогло построить сценарий трансгендерного перехода в части паспортной смены пола.

\section{Определение поля и этапы смены паспортного пола}

На основе включенного наблюдения, а также анализа экспертных интервью и содержания закрытых чатов, в которых общаются трансгендерные люди, опишем поле. Путь, проходимый трансгендерными людьми при переходе включает несколько типов акторов (количество и последовательность могут варьироваться). Первое - это работники медицинского или околомедицинского учреждений, где совершающий переход встает или не встает на учет, получает или не получает справку (психоневрологический диспансер, РХАС, независимые комиссии и другое). Второе - работники загсов и судов, куда трансгендерный человек обращается с целью смены документов. Также сюда можно отнести работников учреждений, отвечающих за смену других документов (например, МФЦ). Промежуточным звеном выступают работники учреждений или коммерческих предприятий, при контакте с которыми необходима демонстрация документа (кассир в супермаркете, потенциальный или реальный работодатель). Неоднозначна роль следующего типа актора работники медицинских учреждений. С одной стороны, это “волшебные 
помощники" героев (по классификации В. Я. Проппа) [5]. Они изначально настроены положительно к трансгендерному человеку, обладают необходимой квалификацией. Ситуации общения с помощниками почти никогда не случайны. Чаще всего, на них выходят по совету других трансгендерных людей или других “волшебных помощников”. С другой стороны, это представители системы, столкновение с которыми может быть как случайным (попал в больницу с проблемой, не относящейся к трансгендерности), так и необходимой частью трансгендерного перехода (например, сдача анализов или регулярное введение тестостероносодержащего препарата в поликлинике). Сюда относятся работники поликлиник и больниц, врачи-эндокринологи (для получения препарата нужна обязательная справка от данного врача), сотрудники аптек, центров пластической хирургии и других медицинских учреждений.

Поле характеризуется частичной закрытостью. Информация о медицинских услугах для трансгендерных людей не представлена в открытом доступе. На сайтах медицинских учреждений, поликлиник и других нет информации об услугах для транслюдей. Группы в соцсетях разделяются на открытые и закрытые. Частично это можно объяснить вопросами безопасности как для самих врачей, так и для их потенциальных пациентов.

Поле стремится быть закрытым. Оно не четко структурировано и его состав варьируется в зависимости от региона и/или человеческого фактора. Также со стороны самих трансгендерных людей можно говорить скорее о стремлении к закрытости, что связано как с самой спецификой трансгендерного перехода и стремлением борьбы с дисфорией, так и с соображениями безопасности.

Также можно отметить несовершенство правового регулирования и распространение неформальных практик. Услуги получаются тремя способами:

1) полностью легально;

2) частично легально;

3) нелегально (например, самоназначение препаратов заместительной гормонотерапии).

В поле существуют известные акторы, такие как Дмитрий Дмитриевич Исаев, являющийся одновременно и исследователем трансгендерных людей, и экспертом, и организатором комиссии по постановке диагноза. Но тут надо отметить региональную составляющую: комиссия находится в Санкт-Петербурге, она доступна для жителей других регионов, но поскольку 
для ее прохождения необходимо пребывание в городе и оплата комиссии, она недоступна для части трансгендеров. Также можно говорить о некоторых известных врачах и сетях аптек, продающих препараты. Но здесь также необходимо отметить, что услуги оказываются этими лицами или организациями в закрытом или полузакрытом порядке. Тем не менее практически все акторы функционируют в правовом поле, связаны между собой (например, к эндокринологу нужно идти со справкой о диагнозе, он дает направление на анализы, по них же он выписывает рецепт, который принимает аптека).

Сам процесс трансгендерного перехода можно сравнить с квестом (также, например, как описывает путь тела от места смерти до могилы Мохов С.В.) [6]. Этот путь содержит определенные этапы в своей идеальной модели (модель может варьироваться в зависимости от человека). Часто реальная ситуация оказывается не такой, как представлялась респонденту в начале перехода. К некоторым этапам приходится возвращаться повторно, что бывает связано с различными причинами. Основной является слабость бюрократического аппарата [7].

Также нельзя представить этот процесс в виде схемы. Участвовавшим в исследовании респондентам предлагалось зарисовать свой переход. По итогам не обнаружилось единой схемы и общей логики именно в очередности конкретных этапов смены документов.

Выявлены стандартные этапы смены документов (но не все из них и не обязательно в этой последовательности проходятся трансгендерными людьми).

1. Постановка на учет в инстанцию, которая предположительно сможет поставить диагноз в ходе обследования или же как минимум провести обследование (например, психоневрологический диспансер).

2. Пребывание в стационаре (в редких случаях).

3. Сбор документов и справок, необходимых для прохождения комиссии (в подавляющем большинстве случаев включает посещение врачей).

4. Получение справки с диагнозом.

5. Посещение клиники для операции по мастэктомии и получение справки о проведении органоустраняющей операции (опционально, но получившие такую справку имеют больше шансов на смену документов в загсе).

6. Сбор документов для подачи заявления на смену имени в загс для выдачи справки о перемене имени (опционально) и нового свидетельства о 
рождении.

7. Подача заявления в загсе.

В случае отказа: 7.2 Получение отказа.

7.3 Подача заявления в суд.

7.4 Заседание суда.

7.5 Получение решения суда.

7.6 Повторная подача заявления в загсе.

8. Получение свидетельства о рождении.

9. Подача заявления на получение нового паспорта.

10. Получение нового паспорта.

11. Замена остальных документов.

Безусловно, указанные пункты отражают общую картину лишь схематично. В зависимости от конкретных жизненных ситуаций пункты могут дополняться. Например, в случае наличия у трансгендерного человека ребенка есть практика переоформления доверенности с “себя старого” на "себя нового".

Проект правовой помощи трансгендерным людям в рамках своего мониторинга дискриминации [8] выделяет несколько пунктов, которые могут дать понятие о дополнительных моментах, где в ходе процесса смены паспортного пола может понадобиться обращение к бюрократическому аппарату.

“Трудовые отношения (отказ в приеме на работу; увольнение; требования ходить в одежде, соответствующей паспортному полу; отказ в использовании предпочитаемого имени и т.д.)

Образование (требования ходить в одежде, соответствующей паспортному полу; отчисление из школы или университета; требование посещать уроки физкультуры с группой, соответствующей паспортному полу и т.д.)

Коммерческие и муниципальные услуги (отказ оказывать услуги в магазине/банке/на почте/на транспорте из-за несоответствия внешности паспортным данным или трансгендерного статуса и т.д.)

Здравоохранение (отказ в оказании медицинской услуги; отказ в выдаче медицинской карты из-за данных в паспорте и т.д.)

Родительские права (необходимость раскрывать личные данные и трансгендерный статус при подтверждении отношения к ребенку; отказ в признании родителем ребенка в связи с данными в документах ребенка или родителя; отказ в смене документов или постановке диагноза из-за наличия 
детей; угрозы и попытки ограничить в родительских правах из-за трансгендерности)

Требования развода (в случае требования развода для постановки диагноза и/или смены документов)"

Большинство из указанного выше было упомянуто в интервью трансгендерными людьми, с которыми и проходила работа в рамках исследования. Респонденты по-разному оценивали важность тех или иных столкновений с бюрократическим аппаратом.

В ходе анализа интервью были выявлены коды, на основе которых были определены категории, которые помогли выявить наиболее важные для респондентов моменты при взаимодействии с бюрократическим аппаратом во время трансгендерного перехода.

\section{Анализ категорий, выявленных в интервью с трансгендерными людьми}

Было проведено 10 интервью с респондентами из разных регионов РФ. В ходе анализа материалов интервью было выявлено 14 основных линий.

Выделим основные линии, разделив их на 2 категории. К первой категории относятся стадии перехода:

1. самопрезентация

2. точка начала

3. сценарий смены документов

4. отношения с чиновниками

5. нестандартность поведения чиновников

6. отношения с другими представителями бюрократического аппарата

7. помощники/помехи

8. отношение к респонденту на разных стадиях транзишена

Ко второй - темы:

1. важность смены документов

2. завершенность смены документов

3. помощники/помехи

4. семья, учеба, работа

5. открытость/закрытость

6. определение основной проблемы при смене документов в России (при транзишене)

7. решение проблемы 


\section{Выводы}

Процесс смены паспортного пола трансгендерными людьми имеет четкий сценарий, но вариативен в ряде пунктов (в случае, если человек не проходит испытание и ему приходится возвращаться на предыдущий этап или искать иной путь). Мы не можем разделять трансгендерных людей и трассексуалов, не можем говорить о том, что смена паспортного пола необходима только бинарным людям, поскольку в исследовании в качестве респондентов присутствовали также люди, определяющие себя как небинарные (или упоминающие это другими словами), но их истории не имели кардинальных отличий от бинарных людей.

Существует четко понимаемое респондентами начало и конец пути в рамках смены паспортного пола: от первого обращения в соответствующую инстанцию до получения паспорта.

Нет четких негативных или положительных акторов в поле. Отношение к акторам может меняться как у одного респондента в процессе перехода, так и у различных респондентов относительно одного актора.

Количество положительных решений по делам, связанным со сменой паспортного пола, - самое высокое из всего массива дел, которые ведут гражданские юристы. Тем не менее для трансгендерных людей в большей степени характерно тяжелое переживание необходимости обращаться в суды.

По итогам включенного наблюдения: FTM и MTF отличны по своему поведению, стилю общения, запросам на поддержку и артикуляции проблем. Гегемонная маскулинность и борьба с ней наблюдается у респондентов поразному на разных стадиях перехода. В начале - следование необходимой роли, затем - поиск себя. Все респонденты выступают против существующего порядка контроля над телом и предлагают различные пути решения.

\section{Список литературы}

1. Legal Gender Recognition in Europe. Richard Köhler, Julia Ehrt With a jurisprudence section compiled by Constantin Cojocariu. November 2016.

2. Brandon J. Hill, Richard Crosby, Alida Bouris, Rayna Brown, Trevor Bak, Kris Rosentel, Alicia VandeVusse, Michael Silverman, Laura Salazar. Exploring Transgender Legal Name Change as a Potential Structural Intervention for Mitigating Social Determinants of Health Among Transgender Women of Color. Sexuality Research and Social Policy. March 2018, - Volume 15, - Issue 1, pp 25-33. 
3. МКБ. Международная классификация болезней 10-го пересмотра: http://mkb-10.com

4. Greta R. Bauer, Ayden I. Scheim, Jake Pyne, Robb Travers and Rebecca Hammond. Intervenable factors associated with suicide risk in transgender persons: a respondent driven sampling study in Ontario, Canada. // BMC Public Health. - June 2015.

5. Пропп В. Я. Морфология (волшебной) сказки. Исторические корни волшебной сказки / В. Я. Пропп ; коммент. Е. М. Мелетинского, А. В. Рафаевой; сост., науч. ред., текстол. коммент. И. В. Пешкова. - М.: Лабиринт, - 1998.

6. Мохов С. В. Рынок ритуальных услуг в современной России: поломка похоронной инфраструктуры как властный ресурс. // Социология власти. 2016. - №4.

7. Рогозин Д. М. Мировоззрение государственных и муниципальных служащих Российской Федерации: профессиональная этика, политические воззрения, особенности взаимодействия с центральной властью и местным населением. - Москва, - 2014.

8. Трансгендерные люди в российском обществе. Исследование 20162017. - СПб: Проект правовой помощи трансгендерным людям, - 2018. - 92 с.

(С) Д.Н. Теодори, 2021 